Rev. High Pressure Sci. Technol., Vol. 7 (1998) 1156 1158

\title{
In Situ Spectroscopic Studied on Supercritical Water and Aqueous Solutions
}

\author{
Y. Ikushima, K. Hatakeda, O. Sato, N. Saito, and T. Aizawa \\ National Industrial Research Institute of Tohoku, Nigatake, Miyagino-ku, Sendai 983-0036, Japan
}

\begin{abstract}
The structure of supercritical water and aqueous solutions has been examined up to $510{ }^{\circ} \mathrm{C}$ and $40 \mathrm{MPa}$ with in situ laser Raman spectroscopy. Just near the critical point, the maximal concentration of the symmetric $\mathrm{OH}$ stretching is obtained although the breakdown of the hydrogen-bonding network occurs. Consequently, short-lived tetrahedral configurations accompanied by large fluctuations of the structure are significantly formed and become possible along with dimers monomers. The spectra of an aqueous zinc nitrate solution reveal that the replacement of $\mathrm{H}_{2} \mathrm{O}$ molecules in the solvation shell of $\mathrm{Zn} 2+$ by a nitrate ion is significantly promoted at higher temperatures above $300{ }^{\circ} \mathrm{C}$ at 30 $\mathrm{MPa}$. The average number of water molecules bound to the zinc ion is decreased to about 3 at $380{ }^{\circ} \mathrm{C}$ from 6 .
\end{abstract}

[Supercritical water, laser Raman spectroscopy, structure, hydrogen bonds, electrolyte solution]

\section{Introduction}

Much attention has recently been drawn to various reactions like the destruction of hazardous wastes in supercritical water $\left(\mathrm{SW} ; \mathrm{P}_{\mathrm{c}}=22.1 \mathrm{MPa}, \mathrm{T}_{\mathrm{c}}=374{ }^{\circ} \mathrm{C}\right.$ ) [1] because the great advantage of the reaction medium is that it can solubilize substantial amounts of organic compounds, thereby removing interphase transfer and leading to fast reaction rates. However, despite a great deal of the experimental work, the lack of data on the nature of SW including the hydrogen bonding hinders our understanding of reaction mechanism in SW medium on microscopic level as well as the properties and structure of SW. Raman spectroscopy is a very useful tool for clarifying molecular structures at high pressures and temperatures[2]. In this study, we try not only to examine the character of hydrogen bonding of SW, especially in the near-critical region, but to describe the behavior of an aqueous zinc nitrate solution, up to $40 \mathrm{MPa}$ and $510{ }^{\circ} \mathrm{C}$ because an understanding of aqueous salt solutions at high temperatures is important in geochemistry and corrosion problem.

\section{Materials and Methods}

The main difficulty in Raman spectroscopic investigation under SW state has been the design of suitable optical cells withstanding severe conditions sometimes with corrosive atmosphere. Figure 1 shows a high-pressure and hightemperature optical Raman cell used. The body of the cell was fabricatedfrom a monoblock of Inconnel 718 and has an internal volume of $0.5 \mathrm{~m}$. Optical access was given by way of three sapphire windows which are sealed to the cell using gold-plated metal seals. Temperature was controlled using electric heaters. Triply distilled and degassed water is loaded into the cell using a high-pressure liquid pump and pressure control was achieved by a back pressure regulator. A $1.7 \mathrm{M} \mathrm{Zn}\left(\mathrm{NO}_{3}\right)_{2}$ aqueous solution was prepared gravimetrically from the triply distilled and degassed water. The light source was a $150 \mathrm{~mW} \mathrm{Ar+ion} \mathrm{laser}$ operating at $488 \mathrm{~nm}$. A $90^{\circ}$ scattering geometry was used with the cell illuminated from below. The detector was a $\mathrm{CCD}$ cooled at $-120{ }^{\circ} \mathrm{C}$ and the exposure time was $10 \mathrm{sec}$.

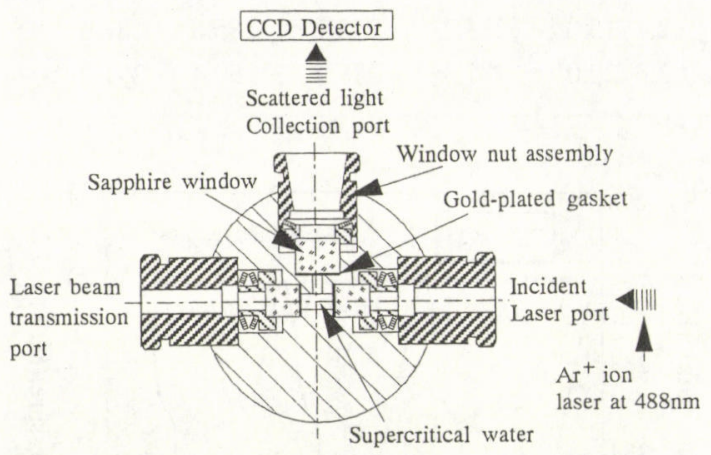

Fig. 1. Cutaway view of high-pressure and high-temperature optical Raman cell.

\section{Results and Discussion}

In the Raman spectrum only the symmetric stretching is very intense, e.g., the frequencies $\left(\nu_{1}\right)$ of $\mathrm{H}_{2} \mathrm{O}$ monomer and dimer are assigned to 3657 and $3652 \mathrm{~cm}-1$, respectively [3,4]. The asymmetric $\mathrm{OH}$ stretching at $3756 \mathrm{~cm}^{-1}$ is active in the IR spectrum, while the Raman spectrum requires strong laserpowers of $5-10 \mathrm{~W}$ at $488 \mathrm{~nm}$ for the detection [5]. Figure 2 shows the Raman spectra at $50,350,375$ and $450{ }^{\circ} \mathrm{C}$ and at $40 \mathrm{MPa}$. The spectra were exactly deconvoluted using three Gaussian fits at 50,350 and $375{ }^{\circ} \mathrm{C}$ and two Gaussian fits at $450{ }^{\circ} \mathrm{C}$. At $50{ }^{\circ} \mathrm{C}$ the main bands were observed near 3450 $\mathrm{cm}-1$. At temperatures higher than $350{ }^{\circ} \mathrm{C}$ main bands were observed over $3500 \mathrm{~cm}^{-1}$. In this study from liquid water at room temperature to $\mathrm{SW}$ at most six Gaussian components were obtained in the rough neighborhood of ( I ) 3220, (II )3420, (III)3500, (IV)3550, (V)3615, and (VI) above $3615 \mathrm{~cm}$ 1. Increase in temperature leading to the disorder of the $\mathrm{H}$ atoms induces reorientation of some $\mathrm{OH}$ oscillators, in which the $\mathrm{H}$ atom is located halfway between the two acceptor oxygens and the bifurcated hydrogen bonds (BHB) corresponding to a shallow 
basin in the potential curve are formed between three molecules. Actually the $\mathrm{BHB}$ hydrogen makes two intermolecular contacts and these contacts are closer by ca. $0.3 \AA$ than the normal van der Waals contacts [6]. The results of recent neutron diffraction data [7] provided an evidence for the existence of $\mathrm{BHB}$, suggesting that the appearance of a discernible shoulder at $2.2 \AA$ in the pair correlation function $\mathrm{g}_{\mathrm{OH}}(\mathrm{r})$ is observed. The increased coordination of hydrogen shows a blue shift in the frequency of $3220 \mathrm{~cm}^{-1}$ assigned to liquid water, and the $\mathrm{OH}$ stretching band at $3420 \mathrm{~cm}^{-1}$ is considered to correspond to the BHB. This assignment is further supported by a previous work [5]. Here the components (II) and (III) are assigned to $\mathrm{BHB}$ between nearest- and higher-neighbor molecules, respectively. However, at higher temperatures of 350,375 and $450{ }^{\circ} \mathrm{C}$ in Fig. 2 the bands near 3520 and $3600 \mathrm{~cm}^{-1}$ were observed. The increased thermal agitation seems to cause further orientation from the $\mathrm{BHB}$, in which the non-bifurcated $\mathrm{H}$ atoms orient towards the center of the lateral triangle. They are located outside van dear Waals contact $(2.7 \AA)$, being $3.4 \AA$ away from the second-neighbor oxygens, and hence the BHB with the free $\mathrm{OH}$ groups, that is, non-hydrogen-bonds (NHB) become predominant in the tetrahedral coordination. Thus, components ( V) and (V) seem to correspond to $\mathrm{H}_{2} \mathrm{O}$ molecule having one proton which does not take part in nearly-linear and linear hydrogen bonding, respectively. Note that another $\mathrm{OH}$ forms only a $\mathrm{BHB}$ because the apex angle of the $\mathrm{H}_{2} \mathrm{O}$ molecule is $104.5^{\circ}$. The component (VI) is assigned to the dimer or monomer molecule. The structure of hydrogen bonding will be analyzed according to the above-mentioned assignment.

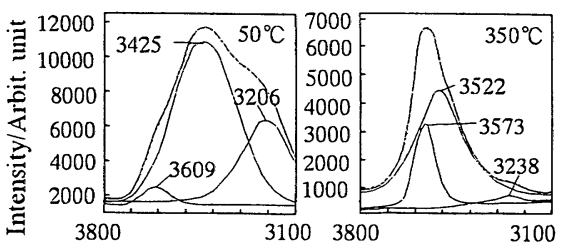

Wave number $/ \mathrm{cm}^{-1}$ Wave number/cm ${ }^{-1}$

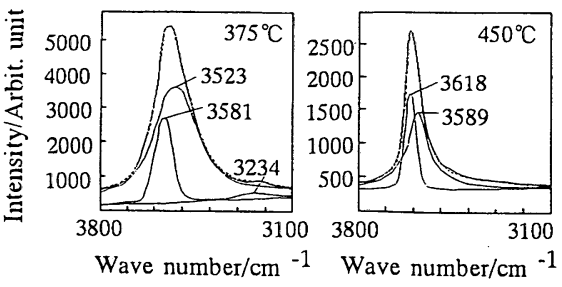

Fig. 2. Examples of Raman spectra at a constant pressure of $40 \mathrm{MPa}$. Dots are experimental data and solid lines correspond to deconvoluted Gaussians and their sum.

Among many points that should be elucidated, a significant question is whether the hydrogen bonds in SW exist, especially near the critical point, or the tetrahedral coordination of $\mathrm{O}$ atoms is still predominant. Figure 3 shows the intensities and full width at half height (fwhh), and the frequency of the maximum intensity $\left(\nu_{\max }\right)$ of components (III), (IV), (V), and (VI) as functions of temperature from 350 to $510{ }^{\circ} \mathrm{C}$ and density at $22.6 \mathrm{MPa}$. The $\nu_{\max }$ of component (VI) reaches almost constant over $3630 \mathrm{~cm}-1$ above $400{ }^{\circ} \mathrm{C}$, and dimers and monomers substantially coexist at equilibrium in addition to the NHB structure. The temperature dependence of the intensity is interesting. Especially, the intensities of components (V) and (V) once increased just slightly above the critical temperature $\left(\sim 380{ }^{\circ} \mathrm{C}\right)$ and were recommenced to decrease with a further increase in temperature. An X-ray scattering study [8] of SW revealed that the peak at $4.5 \AA$ characteristic for the distance between the vertices of the tetrahedron disappears near the critical temperature and with the further temperature rise the peak reappears. The appearance of the peak located at $\sim 4.5 \AA$ in $g_{0 O}(\mathrm{r})$ should be an evidence for tetrahedral ordering of water molecules. This temperaturedependence is very similar to that for our results in Fig. 3, and the hydrogen bonding specifically proceeds to break at the critical temperature. The decrease in intensity near the critical temperature might be also due to critical opalescence.

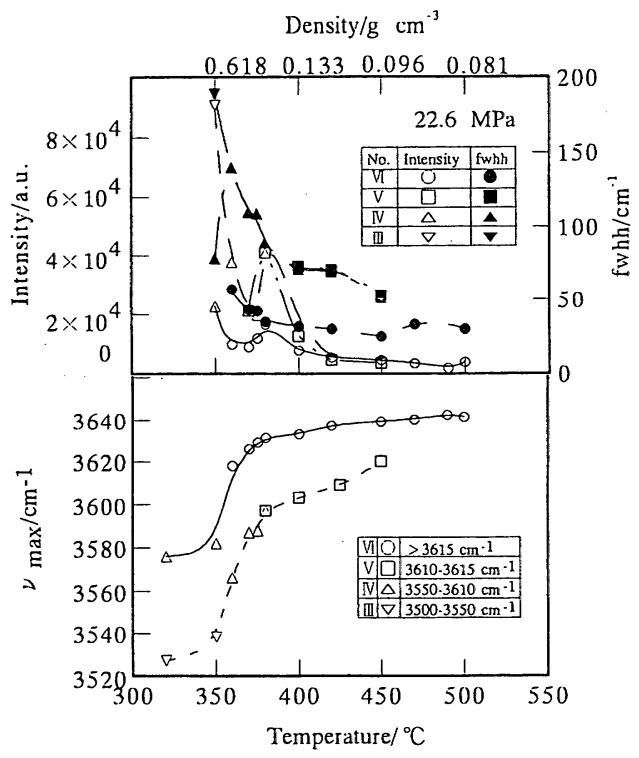

Fig. 3. Intensities, half-widths and $\nu_{\max }$ frequences assigned to components (III), (IV), (V) and (VI) as functions of temperature and density at $22.6 \mathrm{MPa}$.

Figure 4 shows the temperature-dependence of the frequency of the maximum intensity ( $\nu_{\text {max }}$ ) for the component (IV), (V ), or (VI) at pressures of 20.0, 22.6, 23.5, 30.0, and 40.0 MPa. As the temperature is raised, the wave number shifted towards higher frequency, especially in the near-critical region at 23.5 $\mathrm{MPa}$ or below. The higher pressures(densities) at the same 
temperature lead to shifts to lower frequencies as expected. At $40 \mathrm{MPa}$ the wave number at $\nu_{\max }$ reaches $3618 \mathrm{~cm}^{-1}$ at $450{ }^{\circ} \mathrm{C}$ , and the $\mathrm{NHB}$ is predominantly formed. On the other hand, at lower pressures below $30 \mathrm{MPa}$ the wave numbers reach constant over $3630 \mathrm{~cm}-1$ above ca. $400{ }^{\circ} \mathrm{C}$, which is between $3657 \mathrm{~cm}$ 1 for isolated $\mathrm{H}_{2} \mathrm{O}$ molecule and $3615 \mathrm{~cm}-1$ for the NHB, and dimers (or monomers) in addition to the NHB structure should substantially exist in equilibrium. Furthermore, in the nearcritical region the $\nu_{1}$ frequencies are coming close to those assigned to the dimer or freely rotating monomer structures, and the short-lived tetrahedral configurations [9] may be regenerated, by reference to the results in Fig.3, and become feasible to coexist with these less bonded structure elements. At higher pressures, a similar but slight change from the component (IV) to (V) occurs; however, the tetrahedral configuration is predominant even at a higher temperature of $450^{\circ} \mathrm{C}$.

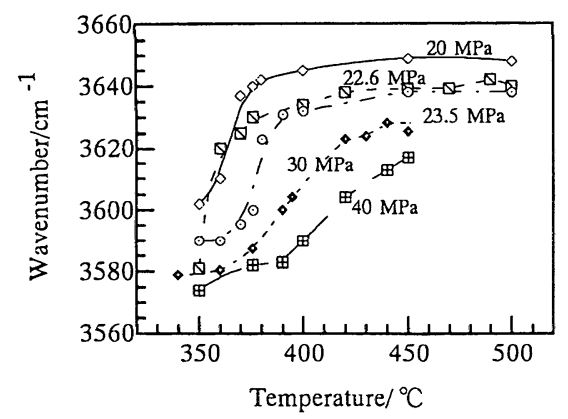

Fig. 4. The frequency of the $\nu_{\max }$ as a function of temperature at different pressures.

Figure 5 shows the temperature dependence of relative intensity of the bound species against the free species in an aqueous $1.7 \mathrm{M} \mathrm{Zn}\left(\mathrm{NO}_{3}\right)_{2}$ solution at a constant pressure of 30 $\mathrm{MPa}$. The Raman bands of nitrate suggest that the $\mathrm{NO}_{3}$ - ion is present in at least two different sites, one is in an environment of solvent-separated ion pairs, $\mathrm{Zn}{ }^{2}+\cdot \mathrm{H}_{2} \mathrm{O} \mathrm{NO}_{3}{ }^{-}$, as the free species, and another one is in contact with the $\left[\mathrm{Zn}\left(\mathrm{H}_{2} \mathrm{O}\right)_{n} \mathrm{NO}_{3}\right]$ + , as the bound species. The ratio of nitrate bound to nitrate free can be estimated from the computer-resolved spectral analysis in the $\nu_{1}$ region of the $\mathrm{NO}_{3}$ - between 1000 and 1100 $\mathrm{cm}^{-1}[10,11]$. An assumption underlying this estimation is that the molar scattering intensities of the both nitrate species are almost the same. As shown in Fig.5, the ratio of nitrate bound to nitrate free is significantly increased above $300{ }^{\circ} \mathrm{C}$, and the replacement of $\mathrm{H}_{2} \mathrm{O}$ molecules in the primary solvation shell of $\mathrm{Zn} 2+$ by the $\mathrm{NO}_{3}$ - was found to be remarkably promoted in the region of higher temperatures. The average number of water molecules bound to zinc ion can be calculated based on the ratio of the intensity of stretching band of the aquated zinc ion at each temperature against the molar intensity of the stretching mode of the hexaaquazinc(II) cation around $390 \mathrm{~cm}-1[10]$. The average number is decreased to about 3 at $380{ }^{\circ} \mathrm{C}$ and $30 \mathrm{MPa}$, and in this high temperature region a transformation from an octahedral, $\mathrm{Zn} 2+\left(\mathrm{H}_{2} \mathrm{O}\right)_{6} \quad \mathrm{NO}_{3}$ - to a tetrahedral configuration, $\left[\mathrm{Zn}\left(\mathrm{H}_{2} \mathrm{O}\right)_{3} \mathrm{NO}_{3}\right]+$ is clarified to occur in the primary solvation shell of $\mathrm{Zn} 2+$. This temperature dependence seems to be strongly dependent on the dielectric constant drop at higher temperatures. Furthermore, the numbers of nearest-neighbor water molecules around $\mathrm{Rb}+$ have recently been reported under supercritical conditions[12].

\section{Conclusions}

Small clusters like dimers could be formed at pressures lower than $30 \mathrm{MPa}$ above $400{ }^{\circ} \mathrm{C}$, while at a higher pressure of $40 \mathrm{MPa}$ an approximately tetrahedral configurations are predominant even at $450{ }^{\circ} \mathrm{C}$. In aqueous zinc nitrate solution at temperatures above $300{ }^{\circ} \mathrm{C} \mathrm{H}_{2} \mathrm{O}$ molecules in the solvation shell of $\mathrm{Zn} 2+$ were replaced by the $\mathrm{NO}_{3}{ }^{-}$and a tetrahedral configuration, $\left[\mathrm{Zn}\left(\mathrm{H}_{2} \mathrm{O}\right)_{3} \mathrm{NO}_{3}\right]+$ is thought to be formed.

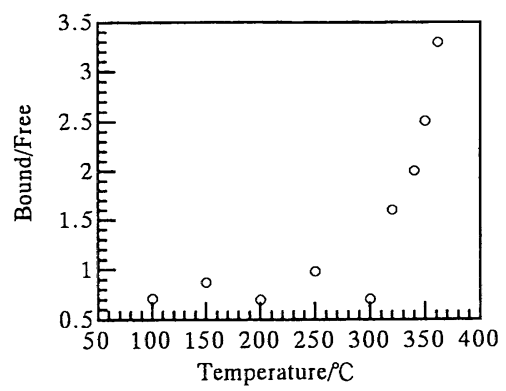

Fig. 5. Temperature dependence of relative intensity of the bound species against the free species in $\mathrm{Zn}\left(\mathrm{NO}_{3}\right)_{2}$ at $30 \mathrm{MPa}$.

\section{References}

[1]K. Hatakeda, Y. Ikushima, S. Ito, O. Sato, and N. Saito Chem.Lett. , 1997, 245.

[2]P.T.T. Wong, Vibrational Spectra and Structures, Vol 16 , Elsevier, Amsterdam,1987.

[3]W.S. Benedict, N.Gailar, E.K.Plyler, J.Chem.Phys. ,1956, 1139.

[4]M.A. Buldakova, I.I. Matrosov, T.N.Popova, J. Appl. Spectrosc., 44, 42(1986).

[5]G.E. Walrafen, Y.C. Chu, J.Phys. Chem. ,99, 11225(1995).

[6]P.A. Giguere, J.Chem. Phys. , 57, 4835(1987).

[7]P. Postorino, R.H. Tromp, M.-A. Ricci, K. Soper, G.W.Neilson, Nature, 366, 668(1993).

[8]Yu.E. Gorbaty, Y.N. Demianets, Chem. Phys. Lett. , 100, 450(1983).

[9]A.V. Okhulkov, Yu.N. Demianets, Yu.E.Gorbaty, J. Chem. Phys. , 100, 1578(1994).

[10]D.E. Irish, T. Jarv, Appl. Spectrosc. , 37, 50(1983).

[11]P.D. Sphon, T.B. Brill, J. Phys. Chem. , 93, 6224(1989).

[12]J.L.Fulton, D.M. Pfund, S.L. Wallen, J. Chem. Phys., 105, 2161(1996). 